\title{
Dilemas e incidencias de la cosa juzgada expansiva en clave de efectividad de los Procesos Colectivos en Argentina Por Diego Exequiel Valenzuela
}

\section{I).- Introducción}

Es sabido que la realidad social se desarrolla a una velocidad asombrosa, máxime en los últimos tiempos a raíz de los desarrollos tecnológicos, lo que ha conllevado a configurar una especie de utopía para los ordenamientos jurídicos clásicos, que pretenden acompañar esos hechos. En este marco es que aparecen en escena los denominados Procesos Colectivos -los que especialmente a raíz de diversos sucesos de notoria trascendía socialhan generado un despertar acerca de su necesidad de regulación y de los distintos aspectos que los constituyen, en contraposición con los tradicionales procesos individuales o litisconsorciales.

El foco de análisis se centrara sobre el último eslabón de la cadena constitutivo del proceso judicial, es decir, la sentencia y el grado de alcance que se le haya adjudicado, en relación a los sujetos representados o no en el marco de un litigio colectivo, y asimismo, como ello incide en mayor o menor medida, en una adecuada protección de los derechos y garantías en juego y su correspondiente eficacia como instrumento de justicia.

En relación a ello, se ponderara principalmente, lo resuelto en el caso "Centro de Estudios para la Promoción de la Igualdad y la Solidaridad y otros e/ Ministerio de Energía y Minería s/ amparo colectivo" (Expte. No FLP 8399/2016/CS1), por la Corte Suprema de Justicia de la Nación (en adelante, CSJN), la cual por unanimidad, decidió confirmar parcialmente la sentencia apelada, y declarar la nulidad de las resoluciones 28/2016 y 31/2016 emitidas por el Ministerio de Energía y Minería de la Nación (en lo sucesivo, MINE), delimitando los alcances de su decisión al colectivo de usuarios residenciales, por considerar que no se encuentra plenamente justificado, una afectación al acceso a la justicia para los usuarios "no residenciales" del servicio de gas, por los cuales la parte actora se arrogaba su representación colectiva.

Esta última referencia, será motivo ineludible de tratamiento, máxime cuando se comprende que tal decisión corrompe el verdadero sentido y finalidad que hacen a los Procesos Colectivos, configurándose de tal manera, cierta regresión en materia de derechos de incidencia colectiva y su real tutela judicial efectiva.

En suma, la idea es reflexionar en conjunto, y de manera sistemática, la trascendencia que importan esta clase de procesos y como su correcta evolución en el derecho argentino -en particular, respecto de los efectos subjetivos de la cosa juzgada- pueden contribuir decididamente a mejorar el servicio de justicia y las necesidades que demanda la sociedad.

II).- Situación en Argentina y la necesidad de repensar el instituto de la cosa juzgada en clave colectiva

La idea de los Procesos Colectivos, como vía idónea para canalizar la protección de distintas categorías de derechos, tales como los derechos o interés difusos, de incidencia colectiva en relación a bienes colectivos, y derechos individuales homogéneos, han im- 
plicado una verdadera "revolución" para los distintos mecanismos de los que se sirve el aparato judicial, derivando en una menester evaluación sobre el nivel de efectividad que ellos importan.

Desde la perspectiva histórica, la explosión producida por la expansión de las sociedades industriales modernas ha hecho nacer en forma vertiginosa un nuevo derecho -tanto sustancial como procesal- que debió salir al cruce a novedosas situaciones que la era tecnotrónica puso en primera plana, obligando a repensar varias instituciones y principios, como por ejemplo la legitimación, los alcances de la cosa juzgada, etc., que tuvieron origen en la concepción ultra individualista del siglo decimonónico (Morello et al, 1983:207).

En este sentido, cuando se encuentra lesionado o amenazado de lesión un derecho de incidencia colectiva, su protección demanda de un modelo de proceso diferente al individual que facilite el acceso a la justicia de quienes pretenden la tutela (Sbdar, 2012:351). Este panorama descripto, ha propiciado que desde hace ya hace un tiempo, los procesos colectivos obtuvieran un lugar de interés preferencial en la agenda académica y política de nuestro país, especialmente debido a las consecuencias que la promoción de procesos colectivos puede generar en el balance económico-financiero de las grandes empresas $\mathrm{y}$ al hecho que por medio de estas acciones se puede lograr un importante y profundo control de constitucionalidad y convencionalidad de políticas públicas implementadas mediante leyes y actos administrativos por parte de distintas autoridades de gobierno (Gianni et al, 2016).

En este camino, la experiencia del derecho comparado ha sido y es de un valor inconmensurable, fundamentalmente en lo que respecta a ciertos puntos neurálgicos como la cuestión de la legitimación colectiva, de la representación adecuada y los efectos subjetivos de la cosa juzgada. En este contexto sus innovaciones plasmadas en diversas legislaciones, representan un faro de luz, el cual sin vacilar ha de guiarnos. Particularmente, me refiero a la Regla 23 de las Reglas Federales de Procedimiento Civil de los Estado Unidos, la cual establece una serie detallada de prerrequisitos, a fin de declarar la admisibilidad de una class action (acción de clase), por los cuales quien o quienes pretendan interponer una acción de este tipo, deberán someterse a esta especie de test colectivo, y una vez superado el mismo, se tramitara el proceso respectivo.

Es importante acotar que la tutela de los intereses colectivos tuvo como fuente mediata el modelo brasileño, que fue paulatinamente desarrollándose en ese ámbito territorial, concretamente a partir del año 1965 con la vigencia de la Ley de Acción Popular (Ley 4717), y posteriormente con la Ley 7347 que regula la llamada Acción Pública. Más tarde se sancionaría, la Ley 8078 (del 11/9/1990) llamada Código de Defensa del Consumidor, donde en su art. 8.1 señala que la defensa de los intereses o derechos de los consumidores y de las víctimas puede ser ejercida en juicio en forma individual o a titulo colectivo (Hitters, 2005:752).

En virtud de este análisis, merece una destacada mención el Anteproyecto y posteriormente, Código ModelodeProcesos Colectivos para Iberoamerica (2004), el cual ha recogido mucho de los avances, experiencias y propuestas que se han gestado en distintos Con- 
gresos y debates, de los que han participado distinguidos especialistas en la materia, de tal forma, que con él se pretende contribuir a los distintos países, proporcionando un conjunto de pautas interpretativas que orienten las políticas legislativas y procesales (Gidi, 2003). En lo que respecta específicamente, sobre la regulación que lo distintos mecanismos le han concedido al instituto de la cosa juzgada colectiva, esto es el de las acciones de clase estadounidenses, por un lado y el brasileño - iberoamericano, por el otro, se puede comentar que en el primero, la sentencia se extiende a todo el grupo, sea que la solución final haya resultado favorable o desfavorable al grupo, lo que se conoce como el principio "pro et contra", y sin que la ley haya determinado excepciones a dicha regla. Sin embargo, la jurisprudencia condiciona la claridad de dicha solución, entendiendo que puede replantearse el asunto si se demostrara que la actuación del representante en la defensa de los intereses de la no fue lo suficientemente vigorosa. En el segundo instrumento, el legislador identificó una hipótesis general de "ausencia de representatividad adecuada”, como es la insuficiencia probatoria, y la elevó como causal tarifada de revisión del decisorio colectivo en todos los casos. De ello se deduce, que la técnica empleada por dicho ordenamiento parte de la desconfianza que en el sistema Iberoamericano se tiene sobre el representante, problema que no existe en el derecho anglosajón que pivotea a través de las class actions con un adecuado control de la representación. De ahí entonces la aplicación del apotegma: A mejor representatividad más calidad de la cosa juzgada (Hitters, 2005:774).

En Argentina, la regulación de los procesos colectivos y en particular, de los alcances subjetivos de la cosa juzgada han tenido una evolución atemperada y alternada, porque si se observa el trabajo emprendido por la jurisprudencia que emana de la CSJN (Halabi, 2014) y de otros tribunales provinciales, y asimismo, la labor de la abundante doctrina autoral, se ha avanzado cuanto se ha podido mientras se extiende incomprensiblemente la mora del legislador, tal como lo ha advertido el propio Máximo Tribunal, en oportunidad de dictarse el destacado precedente "Halabi" (Considerando $12^{\circ}$ ), y reiteradamente en sus distintos pronunciamientos, y además, en ejercicio de sus facultades reglamentarias, lo ha manifestado en la acordada 32/2014 por la cual se creó el Registro Público de Procesos Colectivos y la acordada 12/2016 que dispone la aprobación del Reglamento de Actuación en Procesos Colectivos.

La Ley Nacional de Defensa al Consumidor 24.240, y modificada por la Ley 26.361, y la Ley General del Ambiente, disponen en sus disimiles cuerpos normativos, disposiciones relativas al efecto de la cosa juzgada, adoptando como premisa general el efecto erga omnes -aplicándose el principio "secundum eventum litis"- para cuando la sentencia haya sido favorable, mientras que en sentido opuesto, si la misma es rechazada (vg. Por falta de pruebas, se ha optado por excluirse del grupo o clase, etc), la acción puede ser reeditada por los titulares de los derechos individuales afectados (Verbic, 2010).

Debe considerarse que en este tipo de acciones colectivas es fundamental resguardar el derecho al debido proceso legal, más si se pondera, que con ello se trata de evitar que alguien pueda verse afectado por una sentencia dictada en un proceso en el que no ha tenido la posibilidad efectiva de participar (Sbdar, 2012:365). En definitiva, la regulación 
de la cosa juzgada colectiva importa siempre la búsqueda de una solución armónica que permita equilibrar los dos objetivos que tradicionalmente se encuentran en tensión en este ámbito: por un lado, la necesidad de concentrar el enjuiciamiento de pleitos colectivos o seriados, a través de la extensión vinculante de la sentencia al grupo afectado por una misma problemática; y, por el otro, la exigencia de preservar la garantía del debido proceso, reconociendo -en determinadas circunstancias- la posibilidad de debatir nuevamente el asunto (Verbic, 2016).

Hasta que dicho punto meridiano, sea efectivamente concretado, previendo la verificación con seguridad de ciertos condicionantes medulares, tales como la representación adecuada con control realizado por parte del juez designado, las notificaciones a los integrantes de la clase y la posibilidad de que aquellos que tengan la voluntad de excluirse -op out- puedan hacerlo, es razonable a mi entender la legislación que impera en la actualidad; sin perjuicio, de prestar aquiescencia a un debate fructífero y superador en miras de las políticas legislativas que se gesten sobre los procesos colectivos y los efectos subjetivos de la cosa juzgada.

IV).- El acceso a la justicia como justificativo "criticable" de circunscripción de los alcances subjetivos de la sentencia

El fallo “CEPIS" ha implicado desde su génesis, un acontecimiento de trascendental relevancia en todos los ámbitos de la sociedad y en el seno los poderes estatales -lo cual no sorprende en su mayoría-, dado que reunía numerosas connotaciones para acarrear esa popularidad. En principio implicaba ser la primera decisión a gran escala adoptada por la CSJN (en ese momento con 4 de sus 5 integrantes) en el contexto de la nueva administración del gobierno nacional. En segundo lugar, el objeto del litigio -la determinación de la tarifa de un servicio público esencial-, el alcance que originariamente portaba la demanda, el crítico estado energético que atraviesa el país, y como ello repercutiría en el costo de vida, en especial de los sectores vulnerables. Asimismo, se percibía cierta expectativa en el ámbito académico, las asociaciones de defensa al consumidor, etcétera, en virtud de que se avizoraba un nuevo escenario, para que el Máximo Tribunal expusiera sus consideraciones y proyecciones sobre los Procesos Colectivos.

Como se logra exhibir, una decisión que presenta estas singulares características, puede dar lugar sin duda alguna, a diversas opiniones, criticas y reflexiones de toda índole, y provenientes de distintos espacios. Por ello en esta oportunidad y a raíz del objeto de este trabajo, se analizara bajo un tamiz critico la sentencia de mérito adoptada por el Tribunal cimero, en particular en cuanto a restringir ó circunscribir los alcances de su resolución al colectivo de usuarios residenciales del servicio de gas (Considerandos $10^{\circ}$ y $12^{\circ}$ ), e impedir que los efectos de la cosa juzgada se extiendan respecto de los usuarios señalados como "no residenciales" dado que según se evaluó:

...no se ha demostrado, ni resulta de manera evidente de las constancias de autos, que el ejercicio individual de la acción no aparezca plenamente posible en atención a la entidad de las cuestiones planteadas (sentencia de esta Corte en la causa FMZ 82203891/2012/1/ RH1 'Sociedad Rural Río V c/ AFIP s/ ordinario', dictada el 4 de agosto de 2016). Esta circunstancia impide tener por corroborada, con una certeza mínima, que se encuentre 
comprometida la garantía de acceso a la justicia que, conforme a la doctrina sentada en el precedente citado, resulta necesaria para habilitar la vía intentada respecto de tales usuarios, por lo que los efectos de esta sentencia no pueden alcanzarlos" (Considerando $13^{\circ}$ ). En primer lugar, comparto la opinión de Gianini el cual estima que el requisito establecido por la Corte, con origen en el fallo "Halabi" (Considerando $13^{\circ}$ ) es de una errónea interpretación del art.43 de la CN, que transforma indebidamente uno de los fundamentos de los procesos colectivos en un requisito sine qua non de procedencia. Se mantiene así una injustificada hermenéutica limitativa en este campo, que contrasta con la elogiable claridad y apertura con la que se receptan en el fallo otras instituciones sustanciales (Gianni, 2016).

Por su parte, la decisión de excluir de los alcances de la sentencia a los usuarios "no residenciales", luego de haberse desarrollado un derrotero judicial de aproximadamente 4 meses, y efectuándose de oficio, sin que ello haya sido materia de agravio por parte del legitimado pasivo, y además, no habiéndose efectuado en la etapa oportuna, como lo es la de certificación, permite concluir como se ha expresado Arballo, "la razón (de la decisión) no es estrictamente conceptual, sino procesal”(Arballo, 2016:133). Esta situación, me permite manifestar con cierta preocupación, que este criterio es equiparable a una denegación de acceso a la justicia, lo cual es paradójico porque es la línea argumental esgrimida por el Tribunal para fallar en aquel sentido. La situación se podría graficar del siguiente modo, al inicio del litigio colectivo los usuarios no residenciales se consideraban representados por los legitimados colectivos -según surge de sus escritos postulatorios-, en ese lapso intermedio se fueron sorteando la distintas etapas preestablecidas judicialmente, hasta llegar ÉL día en que su reclamo sería recibido por la propia CSJN, aquel día en el que albergaban innumerables expectativas, se encuentran con que serian desplazados y con un pasaje de vuelta, que los depositaba en soledad al inicio del litigio. De tal manera, la CSJN para efectuar la división de clases, lo ejecuto mediante el uso de un cuestionable estándar, no previsto más que en su jurisprudencia. Además, este enfoque presenta insalvables cuestionamientos en su validez constitucional y convencional (art. 18 de la Constitución Nacional y 8 de la Convención Americana sobre Derechos Humanos), en tanto restringe el mínimo protectorio que específicamente prevé el art. 43, párrafo segundo de la C.N., al no efectuar dicha distinción de orden restrictivo (Verbic, 2016).

Asimismo, es claro que la interpretación que aborda, no contempla que la tutela grupal contemplada en el art.43 de la CN no sólo sirve para garantizar a los grupos débiles contra todo intento de limitar la protección judicial efectiva de sus derechos, sino también para evitar que se sobreexponga a la judicatura a repetir ineficientemente actuaciones costosas y dilatorias para abordar una multiplicidad infinita de causas sobre cuestiones homogéneas (Gianni, 2016:8).

Estimo atingente, rememorar la circunstancia de que dos de los jueces que votaron la sentencia en el fallo CEPIS -y lo mismo aconteció en el fallo "Abarca" (2016, considerando $29^{\circ}$ )- han sido redactores del nuevo Código Civil y Comercial de la Nación, los Dres. Ricardo L. Lorenzetti y Elena Highton de Nolasco, lo cual me permito analizar que aun- 
que dicho plexo no es de aplicación al caso en cuestión, me genera cierta interrogante la falta de ponderación en especial respecto de los 3 primeros artículos, recopilados en el Titulo Preliminar. Esto me lleva pensar, en que quedo la interpretación teleológica del derecho, con aplicación de un dialogo de fuentes y una decisión razonablemente fundada. Este último aspecto, conlleva la noción de que la razonabilidad implica incorporar la idea de aceptabilidad por parte de la comunidad jurídica a la que se encuentra destinada (Grajales, 2016:90), situación que aquí no me atrevería a afirmar.

En virtud de lo desarrollado, considero sin mayor incertidumbre, que la CSJN por medio de este decisorio dejo plasmado una serie de posicionamientos ideológicos -jerarquizando lo práctico sobre lo justo - que importan un fuerte impacto, teniendo en cuenta su rol institucional como cabeza del Poder Judicial de la Nación.

\section{V).- Conclusión}

La matriz de los Procesos Colectivos, importan hoy en día y quizás más que nunca, una concreta y verdadera necesidad de debate, el cual debe ser esparcido por distintos sectores de la sociedad, en especial en aquellos sitios desde los que se adoptan decisiones, que replicaran sustancialmente en la vida del conjunto de la sociedad.

La idea de la expansión o de los alcances subjetivos de la cosa juzgada, es un tema que reúne una vasta complejidad -tal como lo hemos podido plasmar previamente- y por lo tanto, considero que se debe ir avanzado meticulosa y progresivamente en busca de un mecanismo, que propicie una integral y real eficacia de las sentencias dictadas en el marco de los procesos colectivos. En efecto, este elevado anhelo debe centrar sus objetivos, no solo en los fines sino también en los medios utilizados, de modo tal, que se logre el mentado equilibrio entre la efectividad del servicio de justicia y el derecho a un debido proceso legal, reconocido a nivel constitucional y convencional.

Es cierto, que el derecho a una tutela judicial efectiva lamentablemente camina por la cornisa, a raíz de la carente regulación de normativa específica, que reiteradamente se ha reclamado al Poder Legislativo, con lo cual se menoscaba la seguridad jurídica de la que debe dotarse todo ordenamiento jurídico. En este orden de ideas, se puede aseverar que en los litigios colectivos son decisivos la actitud y el compromiso de los tribunales de justicia, ya que la falta de una regulación adecuada de las herramientas procesales relevantes -entre ellas, el amparo- dificulta la definición de estrategias de litigio, como ocurre con los reclamos de usuarios de servicios públicos o de consumidores. Ante el vacío legislativo, la regulación queda en manos de los tribunales y la suerte de cada caso depende de la actitud de los operadores judiciales, situación que da lugar a decisiones discriminatorias en materia de acceso a la justicia (CELS, 2016).

En cuanto a la decisión, si se quiere polémica, adoptada por la CSJN en el fallo "CEPIS", la misma logra evidenciar una cara de la justicia, que logra encender ciertas alarmas, porque la Corte insiste pese a su retórica aperturista en posiciones limitativas, restrictivas, injustificadas, en materia de legitimación o standing para el litigio colectivo (Gargarella, 2016), con lo cual se vuelve sobre la antigua prédica de quien controla a quien debe controlar. 
Para finalizar, entiendo que el rol de los magistrados de la corte no debe de ceñirse a las meras declamaciones en público (Lorenzetti, 2016)-merecedoras de vivos aplausosrespecto de temas esenciales en un Estado de Derecho, como son el acceso a la justicia y la independencia del poder judicial, sino que además debe existir cierta integridad y coherencia con las acciones propiamente dichas, como en cualquier ámbito de la vida (res non verba).

Siguiendo a Taruffo (2012:23), "son estas sugerencias solo deseos o sueños utopicos? Quizás, pero sin perspectivas utópicas el mundo solo podría cambiar para peor, y la protección de derechos haría lo mismo".

\section{Bibliografía}

Arballo, Gustavo. (2016) Comentario al fallo de la Corte Suprema en la causa CEPIS, Revista Derechos en Acción (ReDeA), edición primavera 2016. Disponible en http:// revistas.unlp.edu.ar/ReDeA/article/view/2833.

Centro de Estudios Legales y Sociales (CELS). (2016) Derechos Humanos en la Argentina: Informe anual 2016. Ed. Siglo Veintiuno. Ciudad Autónoma de Buenos Aires. Disponible en: http://www.cels.org.ar/especiales/informeanual2016/\#acceso-a-la-justicia CSJN. (2016). Abarca, Walter José y otros e/ Estado Nacional - Ministerio Energía y Minería y otros s/ amparo ley 16.986.

CSJN. (2009). Halabi, Ernesto c/ P.E.N. - ley 25.873 - dto. 1563/04 s/ amparo ley 16.986; 21/08/2013, PADEC c. Swiss Medical S.A. si nulidad de cláusulas contractuales, 06/03/2014, "Unión de Usuarios y Consumidores c/ Telefónica Comunicaciones Personales S.A., 23/09/2014, "Municipalidad de Berazategui c/ Cablevisión S.A. s/amparo". Gargarrella, Roberto. (2016). Seis puntos sobre el fallo CEPIS (sobre tarifas). Publicado en Seminario de Teoría Constitucional y Filosofía Política. Disponible en: http://seminariogargarella.blogspot.com.ar/2016/08/6-vinculos-y-diferencias-que-tengo-con.html.

Grajales, Amos. (2016). Interpretación y aplicación del Código Civil y Comercial de la Nación, $1^{\text {a }}$ edición, Ed. Astrea, Ciudad Autónoma de Buenos Aires.

Gianni et al. (2016). Propuesta de bases para la discusión de un proyecto de ley que regule los procesos colectivos. Disponible en : https://classactionsargentina.com/2016/09/06/ propuesta-de-bases-para-la-discusion-de-un-proyecto-de-ley-que-regule-los-procesos-colectivos/

Gianni, Leandro. (2016). La insistencia de la Corte Suprema en un recaudo para la tutela de derechos de incidencia colectiva. S/E. S/P.

(2016) La insistencia de la Corte Suprema en un recaudo para la tutela de derechos de incidencia colectiva (a propósito de los fallos "CEPIS" y "ABARCA"), publicado en La Ley.

Gidi, Antonio et al. La tutela de los derechos difusos, colectivos e individuales homogéneos, hacia un Código Modelo para Iberoamérica. Ed. Porrúa, México, 2003.

Hitters, Juan. (2005). Alcance de la cosa juzgada en los procesos colectivos. Publicado en la Ley, t. 2005-F, sec. S/E. S/P. 
Morello et al. (1983). "La defensa de los intereses difusos" de La justicia entre dos épocas. Ed. Platense, La Plata. Ponencia nacional argentina presentada al XI Congreso Internacional de Derecho Procesal celebrado en Wurzburg, Alemania.

Sbdar, Claudia. (2012). "Las acciones colectivas en el Derecho Argentino" publicado en Procesos Colectivos. Class Actions, I Conferencia Internacional y XXIII Jornadas Iberoamericanas de Derecho Procesal. Buenos Aires.

Taruffo, Michele. (2012). "Notes on the collective protection of rights", publicado en Procesos Colectivos. Class Actions. I Conferencia Internacional y XXIII Jornadas Iberoamericanas de Derecho Procesal. Buenos Aires.

Verbic, Francisco. (S/A). "Procesos colectivos para la tutela del medio ambiente y de los consumidores y usuarios en la Republica Argentina”, Publicado en Civil Procedure Review, Disponible en: www.civilprocedurereview.com.

( S/A). "Propuesta de bases para la discusión de un proyecto de ley que regule los procesos colectivos. Entrega temática 14/17: Cosa Juzgada Colectiva”. Disponible en: https://classactionsargentina.com/2016/09/27/propuesta-de-bases-para-la-discusion-1417-cosa-juzgada-colectiva/

(2016). "Un estándar inconstitucional para el acceso colectivo a la justicia”. Publicado en La Ley. Disponible en: AR/DOC/2622/2016. 